\title{
CAN TOPICAL TRANEXAMIC ACID APPLICATION ON PUMP CORONARY ARTERY BYPASS GRAFT SURGERY REDUCE POSTOPERATIVE BLOOD LOSS
}

\author{
Anand Rampure Vittal Rao1, Muralidhar Anakapalli² \\ 1 Professor, Department of Anaesthesiology, Kannur Medical College. \\ ${ }^{2}$ Assistant Professor, Department of Anaesthesiology, Sri Venkateswara Institute of Medical Sciences.
}

\begin{abstract}
BACKGROUND

Postoperative blood loss remains a major concern in cardiac surgeries. At least $30 \%$ of the times, the cause for blood loss is attributed to diffuse microvascular bleeding.[1] It results from a multifactorial coagulopathy in which the predominant factors are thrombocytopenia, acquired platelet dysfunction, loss of clotting factors, unneutralised heparin and increased fibrinolysis.

Objective- Postoperative blood loss remains a major concern in cardiac surgeries, where microvascular bleeding is an important factor due to various reasons including the use of cardiopulmonary bypass pump [CPB]. Tranexamic acid [TA] is extensively being used in major surgeries to reduce perioperative blood loss. Topical application may reduce the incidence of thrombotic complications in coronary artery bypass surgeries [CABG] as compared to its parenteral supplementation as well as effective in reducing postoperative blood loss.
\end{abstract}

\section{MATERIALS AND METHODS}

This was a prospective, randomised, double-blinded study. Randomisation was done taking lots, where both the Surgeon and the Anaesthesiologist were blinded to drug being used. A total of 60 patients, wherein half the number of patients were allocated to receive the TA 2 gm diluted in $200 \mathrm{~mL}$ normal saline topically as compared to the other half receiving only normal saline. The postoperative bleeding was analysed at 2, 8 and 24 hours.

\section{RESULTS}

There was mild reduction in the amount of blood loss in the TA group during all the periods, $112 \mathrm{~mL} \mathrm{v} / \mathrm{s} 125 \mathrm{~mL}$ at $2 \mathrm{hours}, 343$ $\mathrm{mL} \mathrm{v} / \mathrm{s} 391 \mathrm{~mL}$ at 8 hours and $541 \mathrm{~mL} \mathrm{v} / \mathrm{s} 639 \mathrm{~mL}$ at 24 hours.

\section{CONCLUSION}

In our study, we observed lesser drainage in TA group consistently till 24 hours postoperatively, but without achieving statistical significance.

\section{KEYWORDS}

Postoperative Blood Loss, Tranexamic Acid, Topical Application, Coronary Artery Bypass.

HOW TO CITE THIS ARTICLE: Rao ARV, Anakapalli M. Can topical tranexamic acid application on pump coronary artery bypass graft surgery reduce postoperative blood loss. J. Evolution Med. Dent. Sci. 2018;7(05):571-573, DOI: 10.14260/jemds/2018/130

\section{BACKGROUND}

Postoperative blood loss remains a major concern in cardiac surgeries. At least $30 \%$ of the times, the cause for blood loss is attributed to diffuse microvascular bleeding.[1] It results from a multifactorial coagulopathy in which the predominant factors are thrombocytopenia, acquired platelet dysfunction, loss of clotting factors, unneutralised heparin and increased fibrinolysis. The incidence of re-exploration as reported worldwide is about $2 \%-6 \%{ }^{[2]}$

Tranexamic acid [TA] being a lysine analog is one of the most extensively used antifibrinolytic agent that has proven to reduce bleeding and decrease allogeneic blood transfusions in major surgeries and trauma.[3] TA given systemically reduces the risk of bleeding in cardiac surgeries as well.

'Financial or Other Competing Interest': None.

Submission 18-12-2017, Peer Review 11-01-2018,

Acceptance 18-01-2018, Published 29-01-2018.

Corresponding Author:

Dr. Anand Rampure Vittal Rao,

BT, VGN Minerva Apartments,

Guruswamy Road, Nolambur,

Chennai-600095.

E-mail: dranandrampure@gmail.com

DOI: $10.14260 /$ jemds/2018/130

(c) (i) (3) $\Theta$
This beneficial effect is important in the context of highrisk cardiac surgery, defined as complex surgeries including redo sternotomy, multiple valves replacement, ascending aorta or aortic arch procedures or emergency surgery where the risk for major bleeding, massive blood product transfusion and increased postoperative complications exist. But there are concerns that TA may have prothrombotic and proconvulsant effects, which was more pronounced in open heart surgeries.[4] Theoretically, due to the antifibrinolytic mechanism there is a possibility of an increased risk of thromboembolic events like early graft closure in coronary artery bypass grafting, deep vein thrombosis, pulmonary embolism, myocardial and cerebral infarctions.[5]

The topical application of TA into the pericardial cavity is not so frequent in comparison with its systemic use. The rationale for the topical application is based on Tabuchi et al. Khalil et al[6,7] findings that the local fibrinolytic activity in the pericardial cavity exceeds that in the systemic circulation. A human pericardium contains high levels of tissue plasminogen activator, which under normal/ physiological conditions prevent the formation of adhesions and maintains the fluidity of the pericardial cavity. Surgical tissue manipulations may enhance this local fibrinolytic activity. The anticipated benefit of this way of drug delivery is that the method seems to be both target-directed and potentially safe. The hypothesis that the pericardium acts as a natural barrier 
that minimises the rate of systemic absorption is supported by animal experimental studies with different pharmacological agents. ${ }^{[8]}$ This prospective, randomised and placebo-controlled study was conducted to investigate the effect of topical TA in reducing postoperative blood loss in on pump CABG.

\section{MATERIALS AND METHODS}

This was a prospective, randomised, double-blinded study. Randomisation was done taking lots, where both the Surgeon and Anaesthesiologist were blinded to the drug being used. A total of sixty patients undergoing elective on pump primary CABG were included after taking Institutional Ethical Committee approval. Written informed consent was taken from all the patients. Inclusion criteria were patients between 40 to 70 years old who underwent elective isolated primary CABG, which had Left internal mammary [LIMA] harvesting. Exclusion criteria were patients undergoing combined procedures, redo surgery with renal dysfunction (serum creatinine $>1.5 \mathrm{mg} / \mathrm{dL}$ ), coagulopathy (or platelet count < $100 \times 10^{9} \mathrm{~L}^{-1}$ ), haemoglobin levels $<12 \mathrm{~g} / \mathrm{dL}$, known allergy to TA, recent ( $<7$ days before surgery) intake of anti-platelets (e.g. Aspirin, clopidogrel, non-steroidal anti-inflammatory drugs) or Heparin administration within 48 hours of operation.

A total of 60 patients were studied, 30 in each group. There were 49 male and 11 female patients. Patients were randomly allocated to one of the two groups. Sample size was taken at convenience. Group $\mathrm{T}$ included patients who received $2 \mathrm{gm}$ of TA diluted in $200 \mathrm{~mL}$ normal saline and Group P had patients receiving only $200 \mathrm{~mL}$ normal saline. The solution was poured in pericardial and mediastinal cavity as well as a mop dipped in this solution was applied on the LIMA harvested raw surface before closure of the sternotomy. At least 10 minutes were allowed before the solution was sucked out and the mop removed. Same surgical team was involved in the surgical haemostasis and closure.

All the patients included in this study had same protocol in terms of anaesthetic management as well as Cardiopulmonary bypass [CPB] management. All patients received Heparin 300 units/kg targeting Activated clotting time $[\mathrm{ACT}]>480$ seconds. During CPB, appropriate heparin supplementation was maintained to keep ACT $>480$ seconds. After discontinuation from $\mathrm{CPB}$, heparin reversal was done with Protamine sulphate $1.2 \mathrm{mg} / 100$ units of heparin to achieve an ACT of $<130$ seconds. Packed red blood cell transfusion was done in the postoperative period if the Haemoglobin level fell below $9 \mathrm{gm} / \mathrm{dL}$, platelet transfusion if platelet count was below $100000 / \mathrm{cc}$ in bleeding patients and Fresh frozen plasma (FFP) was transfused $10 \mathrm{~mL} / \mathrm{kg}$ if APTT was elevated.

Hourly chest tube drain was noted for the first 24 hours postoperatively. Apart from this patient's demographics, the number of grafts, cross-clamp time, duration of $\mathrm{CPB}$, incidence of reoperation for bleeding and ICU stay were recorded for all patients.

\section{Statistical Analysis}

Statistical analyses were carried out using Stata version 15.0, chi-square test and student ' $\mathrm{t}$ ' test was used to analyse the data. The $p$ value of less than 0.05 was taken as statistically significant.

\section{RESULTS}

The mean age was 60.1 in $\mathrm{P}$ v/s 58 years in T group, which was not statistically significant between the two groups. The mean weight (72.36 v/s 73.96) was also not statistically significant between the groups. The CPB time $(128.6 \mathrm{v} / \mathrm{s}$ 119.2) and number of grafts (3.53 v/s 3.46) between $P$ and $T$ group were also not statistically significant. These results are presented in-

\begin{tabular}{|c|c|c|c|c|c|}
\hline \multirow{2}{*}{ Variable } & \multicolumn{2}{|c|}{$\begin{array}{c}\text { Control Group } \\
(\mathbf{n = 3 0 )}\end{array}$} & \multicolumn{2}{|c|}{$\begin{array}{c}\text { Tranex Group } \\
\text { (n=30) }\end{array}$} & \multirow{2}{*}{ P value } \\
\cline { 2 - 5 } & Mean & SD & Mean & SD & \\
\hline Age (years) & 60.1 & 8.11 & 58 & 8.17 & 0.307 \\
\hline Weight (kgs) & 72.36 & 10.33 & 73.96 & 9.9 & 0.543 \\
\hline $\begin{array}{c}\text { CPB Time } \\
\text { (min) }\end{array}$ & 128.36 & 35.32 & 119.16 & 34.07 & 0.309 \\
\hline Grafts & 3.53 & 0.77 & 3.46 & 0.89 & 0.759 \\
\hline & & & & & \\
\hline & Males & Females & Males & Females & \\
\hline Gender & 24 & 6 & 25 & 5 & 0.738 \\
\hline \multicolumn{7}{|c|}{ Table 1. Demographic Data } \\
\hline
\end{tabular}

The postoperative bleeding was analysed at 2, 8 and 24 hours. There was mild reduction in the amount of blood loss in the T group during all the periods, $112 \mathrm{~mL} \mathrm{v} / \mathrm{s} 125 \mathrm{~mL}$ at 2 hours, $343 \mathrm{~mL} \mathrm{v} / \mathrm{s} 391 \mathrm{~mL}$ at 8 hours and $541 \mathrm{~mL} \mathrm{v} / \mathrm{s} 639 \mathrm{~mL}$ at 24 hours. But none of these values achieved statistically significant difference between the two groups. The results are presented in-

\begin{tabular}{|c|c|c|c|c|c|}
\hline $\begin{array}{c}\text { Post- } \\
\text { Operative } \\
\text { Bleeding }\end{array}$ & \multicolumn{2}{|c|}{ Control Group } & \multicolumn{2}{|c|}{ Tranex Group } & \multirow{2}{*}{ P value } \\
\cline { 2 - 5 } & Mean & SD & Mean & SD & \\
\hline $2^{\text {nd }}$ hour & 125.43 & 34.33 & 111.66 & 36.86 & 0.140 \\
\hline $8^{\text {th }}$ hour & 391.66 & 123.88 & 343.06 & 158.21 & 0.190 \\
\hline $2^{\text {th }}$ hour & 639.0 & 203.44 & 541.33 & 222.05 & 0.081 \\
\hline \multicolumn{6}{|c|}{ Table 2. Post-Operative Blood Loss } \\
\hline
\end{tabular}

The average packed cell transfused per patient turned out to be 1.53 units in P group as compared to 1.16 units in the $\mathrm{T}$ group. Though Tranexamic group had lesser transfusion per patient, it did not reach statistically significant difference when compared by student ' $\mathrm{t}$ ' test $(\mathrm{P}=0.23)$. This is shown in-

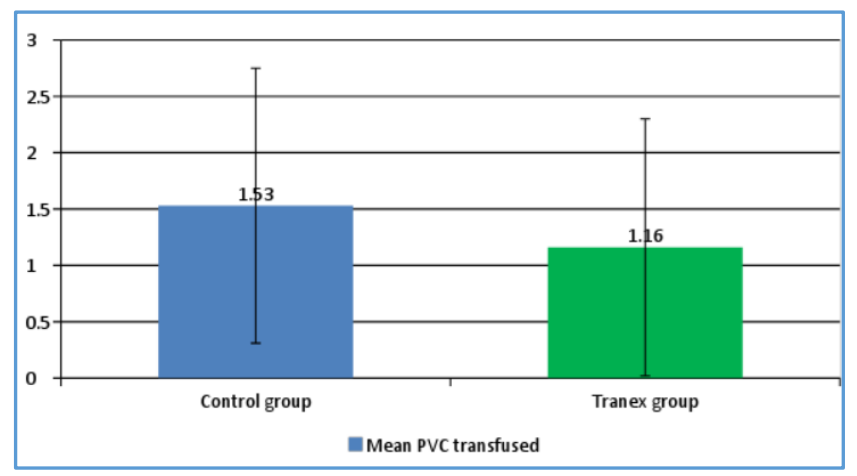

Figure 1. Mean PVC Transfused

Besides packed cell transfusion, there was no statistical difference in the transfusion of fresh frozen plasma and platelets between the two groups. None of the patients under our study required reopening for bleeding postoperatively. 


\section{DISCUSSION}

This study was mainly conducted to evaluate the efficacy of topical TA in cardiac surgeries to reduce postoperative bleeding, as was found in many previous studies.[9] Our study focused on total chest tube drainage 2, 8 and 24 hours postoperatively and packed cell transfusion. Although, a continuous tendency toward lower blood loss in group $\mathrm{T}$ was evident (Table 2). No statistical significance was reached at any time points (2, 8 and $24 \mathrm{hrs}$.) postoperatively. No significant difference in postoperative transfusion of packed red blood cells was found. The anticipated benefit of this way of drug delivery is that the method seems to be both "targetdirected" and "potentially safe." In the majority of studies, the effect on the reduction of blood loss was most pronounced in the first hours after the surgery, which is consistent with a short half-life of tranexamic acid ( $3 \mathrm{~h})$. In our study we observed lesser drainage in TA group consistently till 24 hours postoperatively, but without achieving statistical significance. We did not have any thromboembolic events like graft thrombosis, deep venous thrombosis, perioperative MI etc., as well as any incidence of seizures.

\section{CONCLUSION}

In conclusion, topical TA is a promising drug in reducing postoperative bleeding in cardiac surgeries and safer as compared to parenteral supplementation. We observed clinically some benefit in this form of application in terms of reduction in postoperative blood loss without reaching statistical significance. More studies with larger pool of patients needed to be done to assess its safety and efficacy.

\section{REFERENCES}

[1] Hall T, Brevetti GR, Skoultchi AJ, et al. Re-exploration for hemorrhage following open heart surgery differentiation on the causes of bleeding and the impact on patient outcomes. Ann Thorac Cardiovasc Surg 2001;7(6):352-7.
[2] Ranucci M, Bozzetti G, Ditta A, et al. Surgical reexploration after cardiac operations: why a worse outcome? Ann Thorac Surg 2008;86(5):1557-62.

[3] Simmons J, Sikorski RA, Pittet JF, et al. Tranexamic acid: from trauma to routine perioperative use. Curr Opin Anaesthesiol 2015;28(2):191-200.

[4] Myles PS, Smith JA, Forbes A, et al. Tranexamic acid in patients undergoing coronary-artery surgery. $\mathrm{N}$ Engl J Med 2017;376(2):136-48.

[5] Ovrum E, Holen AE, Abdelnoor M, et al. Tranexamic acid (Cyklokapron) in not necessary to reduce blood loss after coronary artery operations. J Thorac Cardivasc Surg 1993;105(1):78-83.

[6] Tabuchi N, de Haan J, Boonstra PW, et al. Activation of fibrinolysis in the pericardial cavity during cardiopulmonary bypass. J Thorac Cardiovasc Surg 1993;106(5):828-33.

[7] Khalil PN, Ismail M, Kalmar P, et al. Activation of fibrinolysis in the pericardial cavity after cardiopulmonary bypass. Thrombosis Haemostasis 2004;92(3):568-74.

[8] Kolettis TM, Kazakos N, Katsouras CS, et al. Intrapericardial drug delivery: pharmacologic properties and long-term safety in swine. International Journal of Cardiology 2005;99(3):41521.

[9] Vanek T, Straka Z. Topical use of tranexamic acid in cardiac surgery--a review and meta-analysis of four randomized controlled trials. Cor Et Vasa 2013;55(2):e184-e9. 